\title{
Effect of RAP content on flexural behavior and fracture toughness of flexible pavement
}

\author{
Muhammad Mubaraki ${ }^{\mathrm{a}}$ iD
}

\section{S.A. Osman ${ }^{\text {b }}$}

H.E.M. Sallam ${ }^{a, c^{*}}$ iD

a Faculty of Engineering, Jazan University, Jazan 706, Kingdom of Saudi Arabia. E-mail: mmubaraki@jazanu.edu.sa

${ }^{b}$ Faculty of Engineering, Imam Abdulrahman Bin Faisal University, Dammam, KSA. E-mail: sakhair@iau.edu.sa

c On sabbatical leave from Faculty of Engineering, Zagazig University, Zagazig, Egypt. E-mail: hem_sallam@yahoo.com

* Corresponding author

http://dx.doi.org/10.1590/1679-78255516

\begin{abstract}
The use of recycled Reclaimed Asphalt Pavement (RAP) material into flexible pavement contributes to sustainable development with environmental and economic benefits. In the present work, Semi-Circular Bending (SCB) specimen has been adopted to study the flexural strength and mode-I fracture toughness of flexible pavement with and without RAP. Two different resources of RAP, namely KS and KF, with two different percentages ( $20 \%$ and $40 \%$ ) have been examined. Smooth and cracked specimens have been cast to measure the flexural strength and mode-I fracture of flexible pavement containing RAP, respectively. Smooth and cracked specimens for flexible pavement without RAP, as control beams, have been cast for the sake of comparisons. The experimental results showed that, the flexural strength and mode-I fracture toughness of flexible pavement containing 40\% RAP are higher than those of flexible pavement without RAP, for the two types of RAP. Comparison between the of work of fracture calculated based on AASHTO TP 105-13 and AASHTO TP 124-16 showed that, the calculation based on AASHTO TP 105-13 is more accurate than that based on AASHTO TP 124-16. Furthermore, the suggested quad-linear relation to work of fracture predictions is easier and more reasonable for presenting the experimental results especially for the descending part of P-LLD curve than that suggested as exponential curve by AASHTO TP 124-16. For all groups, the type of failure is intergranular-mode fracture.
\end{abstract}

\section{Keywords}

flexible pavement materials, RAP; SCB specimen, flexural strength, mode-I fracture toughness.

\section{INTRODUCTION}

Repeated traffic loading usually induces daily damages of pavement. Many attempts were made to enhance the properties of asphalt pavements by adding fibers, nanofibers, and Polymers (Yoo et al., 2018, Naqi et al., 2018, Abtahi et al., 2010). The use of reclaimed asphalt pavement (RAP) as recycling flexible pavement material becomes more widespread in last three decades (Ulsen et al., 2018, Mubaraki and Sallam, 2018, Al-Qadi et al., 2014). RAP is defined as recycling flexible pavement material to produce reusable asphalt. From environmental, economic, and also technical points of views, RAP is considered one of the most important approaches in the road industry. Therefore, using RAP may be saving virgin materials, decreasing the cost of asphalt, and preserving the environment (Al-Qadi et al., 2014). As is already known, the RAP binder is aged, making it substantially harder than the normal or virgin bitumen used in hot mix asphalt (HMA) mixes. This may, however, be beneficial with respect to controlling rutting because a higher stiffness contributes to improved resistance against rutting. A stiffer binder, however, may increase the propensity to cracking and to reduced tensile strength and fatigue life. Under repeated loadings, RAP greater than $20 \%$ showed harmful 
effects on the fatigue life of pavements, as reported in the literature (Abdulshafi, et al., 2002, Cascione et al., 2010, Johnson et al., 2010, Kim et al., 2009, Li et al., 2008, McDaniel and Shah, 2003, Mogawer et al., 2011).

Ghabchi et al. (2016) evaluated the mechanical properties based on performance of mixes containing different ratios of RAP and/or recycled asphalt shingles (RAS). Generally, dynamic moduli of pavements containing RAP and/or RAS were greater than that of the virgin mix. On the other hand, Mubaraki et al. (2017) simulated the crack resistance in concrete pavement with different RAP contents as a first stage of a project funded by Jazan University, Kingdom of Saudi Arabia. A comparison between their results and that obtained experimentally by Hossiney et al. (2010) showed that the finite element is a suitable tool to predict such materials. In addition, Mubaraki et al. (2013) showed that replacement $10 \%$ of fine aggregate by rubber particles improved the fracture toughness of concrete pavement.

Sallam and Abd-Elhady $(2012,2013)$ examined the reliability of SCB specimens with inclined crack for predicting crack initiation and growth under mixed mode using 3D finite element analysis. For all modes of mixities, the crack path initiated from the pre-crack tip to the position of applied load. Recently, Mubaraki and Sallam (2018) concluded that SCB specimen is a suitable candidate to get the fracture behavior of asphalt materials under static and dynamic mode I loading. They found that the ratio of plane stress to plane strain fracture toughness (KC/KIC) for pavement materials ranged between 3.1 and 6.2. They found that this ratio was directly proportional to the fatigue life of the specimen, i.e. viscoelasticity effect.

Sallam et al. (2014), and Sallam and Mubaraki (2015) examined the reliability of such specimen for predicting fracture toughness of rigid pavements materials using the concept of maximum undamaged defect size $\left(d_{\text {max }}\right)$. Concrete pavements with two different short fibers (glass fiber and steel fiber) were used. According to RILEM Committee 50-FMC, the experimental results showed that the maximum undamaged defect size divided by the maximum aggregate size (MAZ), $d_{\text {max }} / \mathrm{MAZ}$, was greater than unity, i.e. the fracture energy calculated according to RILEM Committee 50- FMC is not computable with the flexural strength of the material. Furthermore, Mousa et al. (2018) generalized the $d_{\text {max }}$ concept to predict the maximum size of imperfection in sandwich materials beyond which the peeling strength of the interface between the layers was decreased. The procedures suggested by Sallam and co-woekers (Sallam, 2003, Al Hazmi et al., 2012, Abou El-Mal et al., 2015) to apply $d_{\max }$ into equation of fracture toughness are as follows: Incorporating the flexural strength of the material (uncracked specimen), $f$, instead of the critical applied stress along with the fracture toughness of the material, $K_{l c}$, hence, $d_{\text {max }}$ instead of the crack length, as shown in the following Eq.:

$$
K_{I C}=Y \sigma_{c r} \sqrt{\pi a}=Y f \sqrt{\pi d_{\max }}
$$

Then,

$$
d_{\max }=\frac{1}{\pi}\left(\frac{K I C}{f}\right)^{2}
$$

One of the main objectives of the current study is to experimentally study the flexural strength and mode-I fracture toughness of flexible pavement with different RAP percentages. Two different resources of RAP, namely KS and KF, with two different percentages (20\% and $40 \%$ ) have been examined. Therefore, two different types of SCB specimens, namely smooth (uncracked) and cracked specimens have been cast to measure the flexural strength and mode-I fracture of flexible pavement containing RAP, respectively. Smooth and cracked specimens for flexible pavement without RAP, as control beams, have been cast for the sake of comparisons. The second objective of the present work is to apply the concept of $d_{\max }$ to evaluate the fracture toughness of flexible pavement containing RAP measured from the SCB specimen suggested by different specifications AASHTO TP105-13 (2015), AASHTO TP 124-16 (2016) and EN 12697-44 (2010). Finally, the methods of computing the work of fracture (area of the ascending and descending parts of load versus load line displacement, P-LLD, curve) suggested by these specifications were evaluated and developed as a third objective of this study. 


\section{EXPERIMENTAL WORK}

\subsection{Constituents materials}

Three types of materials were used in this research, i.e., bitumen, virgin aggregate (VA), and RAP. Bitumen is a byproduct of crude petroleum refining, 60/70 bitumen. To evaluate the asphalt properties a set of laboratory tests were carried out including: penetration, ductility, softening point, flash and fire point and specific gravity. Table 1 presents bitumen properties. Virgin aggregate is a mix of granular particles with different sizes and shapes produced by mechanical crushing of natural or industrial stones. The RAP material was obtained from two ongoing projects, namely the King Saud (KS) Highway and the King Faisal (KF) highway in the Eastern Province, Dammam, KSA. Samples were collected from the two highways as a milling machine cut about $100 \mathrm{~mm}$ from the top of the asphalt layer, and were kept in stockpiles along the road. A representative ten samples from these RAP stockpiles were taken obtained from different locations around the stockpiles to eliminate the effect of segregation. All samples were taken from a depth at least $150 \mathrm{~mm}$ from the surface of the stockpile. Samples were sieved to remove material larger than $50 \mathrm{~mm}$ and discarded. A sample weight of $5 \mathrm{~kg}$ was used for asphalt mix testing and for mix design. Individual samples were extracted for aggregate gradation and asphalt content. This test was done to determine the bitumen content as per ASTM 2172.

Table 1: Bitumen men Physical Properties Tests Results

\begin{tabular}{ccc}
\hline Property & AASHTO Test & Penetration Grade \\
$\mathbf{6 0 - 7 0}$ \\
\hline Penetration at 25 Degrees C, 100g, 5sec. & T-49 & 67 \\
Flash point, Cleveland Open, ${ }^{\circ} \mathrm{C}$, min. & T-48 & 233 \\
Fire point, Cleveland Open, ${ }^{\circ} \mathrm{C}$, min. & $\mathrm{T}-48$ & 243 \\
Solubility in trichloroethylene, percent, min. & $\mathrm{T}-44$ & 99 \\
Specific gravity & $\mathrm{T} 316$ & 1.04 \\
Softening Point $\left({ }^{\circ} \mathrm{C}\right)$ & T 53-09 (2013) & 50.2 \\
\hline
\end{tabular}

According to ASTM specifications, the properties of virgin aggregate were measured including gradation, soundness, crushing value, impact value, flakiness and elongation. The results of these tests were compared to the minimum requirements of the AMANA of Eastern Province specifications, see Table 2. The filler material used as supplement the finest part of the aggregate in asphalt mix design.

Table 2: Basic Properties of virgin aggregate and RAP

\begin{tabular}{|c|c|c|c|c|}
\hline Test & Test used & Virgin Aggregate & RAP (KS) & RAP (KF) \\
\hline Los Angles Abrasion Value, \% & $\begin{array}{l}\text { AASHTO T-96 } \\
\text { ASTM C } 131\end{array}$ & 33.0 & 35.2 & 36.0 \\
\hline Aggregate Crushing Value & & 17.2 & 19.5 & 21.1 \\
\hline Aggregate Impact Value & BS $812-112$ & 30.0 & 34.0 & 35.1 \\
\hline Bulk Specific gravity, & AASHTO T85 & 2.624 & 2.628 & 2.636 \\
\hline Apparent Specific gravity & AASHTO T85 & 2.682 & 2.681 & 2.685 \\
\hline water absorption \% & AASHTO T85 & 0.69 & 1.08 & 1.05 \\
\hline Flakiness index\% & ASTM D4791-05 & 7.8 & 21.1 & 22.0 \\
\hline Elongation index\% & ASTM D4791-05 & 15.1 & 20.4 & 23.3 \\
\hline Clay content, \%, & $\begin{array}{c}\text { AASHTO T-112 } \\
\text { T-112 }\end{array}$ & 0.20 & 0.5 & 0.45 \\
\hline Coating and stripping, & $\begin{array}{c}\text { AASHTO T-182 } \\
\text { T-182 }\end{array}$ & 95 & 95 & 95 \\
\hline Liquid Limit, \% & ASTM D4318 & N.L & N.L & N.L \\
\hline Plastic Limit, \% & ASTM D4318 & N.P & N.P & N.P \\
\hline
\end{tabular}


Specifications of asphalt mixture for wearing course from three different sources were examined. Ministry of Municipality and Rural Affairs specifications for wearing course were used to identify the limits of mix gradation. Different blending for aggregate were carried out using coarse, medium and fine aggregate samples in order to satisfy limits and specifications of Eastern Province (AMANA) as shown in Fig. 1. Figure 1 shows the aggregate gradations blending for AMANA specifications, control mix, and aggregate mix containing $20 \%$ and $40 \%$ of RAP.

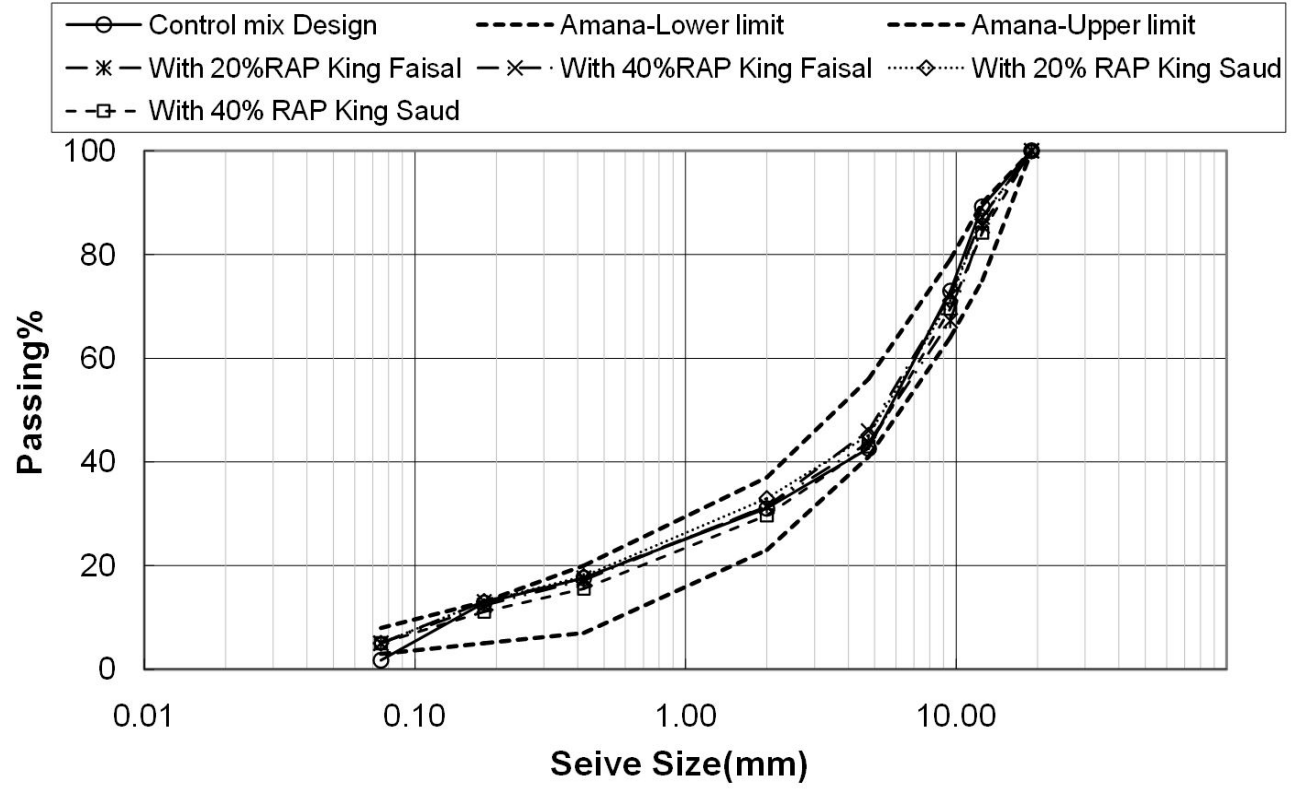

Figure 1: Aggregate blending gradation for control mix, with $20 \%$, and $40 \%$ RAP.

\subsection{Marshall mix design}

Marshall mix design method was used to obtain optimum bitumen content (OBC) for the mixtures. Approximately $1200 \mathrm{~g}$ of mixed aggregate and filler were heated to a 150 ㅇ․ Then bitumen heated to 145 o C. Percentages of $5.0 \%$, $5.5 \%, 6.0 \%, 6.5 \%, 7 \%$ and $7.5 \%$ of bitumen by weight were added to the hot aggregate and thoroughly mixed to obtain the required asphalt mixture; the asphalt mixture then placed in a mold and the specimen then compacted with 75 blows (simulating heavy traffic) on both sides. Three specimens were prepared for each trial bitumen contents. The specimens were delivered to a Marshall test machine one by one to determine their flow values and stability. To determine the corrected stability values of the mixture a correction factor was used.

Extraction tests were carried out to obtain the percentage of bitumen in RAP aggregate, as mentioned above. RAP of $20 \%$ and $40 \%$ by weight of aggregate from the two sources were used to prepare the hot mix specimens with RAP. Then the mix density, voids in mix, aggregates voids and voids with asphalt were calculated. The average values for each of these properties were found for each mix with the different bitumen contents. The properties of asphalt mixtures for control mix and mixes with RAP were plotted graphically versus bitumen content. The optimum bitumen content for all mixes were determined as an average mean from the curves, and then plotted with values checked against the limits set in AMANA specifications. Table 3 showed the results of OBC for all mixes. The OBC decreased as the RAP content increased.

Table 3: OPC and other asphalt mix properties for all mixes

\begin{tabular}{cccccccc}
\hline Mix & OAC $\%$ & Stability, kg & Density, g/cm3 & Flow, mm & Air voids \% & VMA \% & VFB \% \\
\hline Control mix & 6.1 & 1601 & 2.371 & 3.0 & 4.0 & 20 & 75.4 \\
Mix with 20\% RAP-KS & 5.9 & 1430 & 2.401 & 2.95 & 4.00 & 17 & 75.2 \\
Mix with 40\% RAP-KS & 5.7 & 1370 & 2.488 & 2.95 & 4.00 & 18 & 75.0 \\
Mix with 20\% RAP-KF & 5.8 & 1590 & 2.36 & 3.49 & 3.57 & 16.5 & 75 \\
Mix with 40\% RAP-KF & 5.5 & 1540 & 2.37 & 3.3 & 3.91 & $3-5$ & 14 min. \\
AMANA Specifications & 04/jul & 1000 min. & - & $2.4-4.0$ & $30-80$ \\
\hline
\end{tabular}

VMA: Voids in mix aggregate, VFB: Voids filled with bitumen 


\subsection{Retained Marshall Stability}

Marshal tests for stability were carried out for all mixes after been conditioned in water bath at $60^{\circ} \mathrm{C}$ for $30-60$ minutes per ASTM D 1075 specifications. To obtain retained Marshal's stability the specimens were tested after been immersed in water bath at $60^{\circ} \mathrm{C}$ for 24 hours. The retained Marshal's stability results was calculated as the percentage of Marshall Stability for specimen conditioned for 30-60 min to that specimens conditioned for $24 \mathrm{hrs}$ as shown in Table 4 .

Table 4: Results of retained Marshal's stability

\begin{tabular}{cccc}
\hline Mix type & $\begin{array}{c}\text { Marshall Stability for specimens } \\
\text { conditioned at 600C for 30-60 } \\
\text { min }\end{array}$ & $\begin{array}{c}\text { Marshall Stability for } \\
\text { specimens conditioned at } \\
\text { 600C for 24 hours }\end{array}$ & $\begin{array}{c}\text { Retained Marshal's } \\
\text { stability, \% }\end{array}$ \\
\hline Control mix with virgin aggregate & 15.7 & 13.6 & 86.6 \\
Mix with20\% RAP (from King Saud highway & 14.1 & 13.3 & 94.3 \\
Mix with40\% RAP(from King Saud highway) & 13.43 & 13.1 & 97.5 \\
Mix with20\% RAP(from King Faisal highway) & 15.6 & 14.4 & 92.3 \\
Mix with40\% RAP(from King Faisal highway) & 16.1 & 15.5 & 96.3 \\
\hline
\end{tabular}

\subsection{Tensile Strength Ratio (TSR)}

The tensile strength ratio (TSR) is an indication for potential moisture damage. Two sets of samples were prepared to calculate the tensile strength ration according to ASTM D 4867 specifications. One set of specimen maintained dry while the one is saturated in water bath at $600 \mathrm{C}$ for 24 hours. First calculate tensile strength from Equation (3). Then calculate the TSR from Equation 4. The average results of 2 samples presented in Table 5.

$S_{t}=\frac{2 P}{\pi t D}$

Where: $\mathrm{St}=$ tensile strength, $\mathrm{P}=$ maximum load $\mathrm{t}=$ specimen thickness, $\mathrm{D}=$ specimen diameter.

$\operatorname{TSR}=\left(\frac{S_{\mathrm{tc}}}{S_{\mathrm{tuc}}}\right) * 100$

Where: Stc average indirect tensile strength of conditioned specimens and Stuc is indirect tensile strength of unconditioned specimen.

Table 5: The tensile strength ratio (TSR) of all asphalt mixes

\begin{tabular}{cccccccc}
\hline & \multicolumn{9}{c}{ Mix Types } & & \\
\cline { 2 - 5 } Property of mix & $\begin{array}{c}\text { Mix with 40\% } \\
\text { RAP-KF }\end{array}$ & $\begin{array}{c}\text { Mix with 20\% } \\
\text { RAP-KF }\end{array}$ & $\begin{array}{c}\text { Mix with 40\% } \\
\text { RAP-KS }\end{array}$ & $\begin{array}{c}\text { Mix with 20\% } \\
\text { RAP-KS }\end{array}$ & $\begin{array}{c}\text { Control } \\
\text { mix }\end{array}$ & AMANA Specifications \\
Ind. Tensile Str., $\mathrm{kg} / \mathrm{cm}^{2}$ & 6.88 & 6.61 & 6.9 & 6.84 & 6.79 & - \\
TSR, \% & 89.3 & 93.1 & 94 & 85.9 & 88.8 & $\geq 80 \%$ \\
\hline
\end{tabular}

\subsection{Preparation of Semicircular Bend Specimen}

Based on the results of Marshall method for control mixture and mixtures containing $20 \%$ and $40 \%$ RAP specimens produced with a mould $150 \mathrm{~mm}$ in diameter, according to AASHTO specifications $(2015,2016)$. RAP from two sources, the King Saud and King Faisal highways, were used to prepare the specimens. Moulds containing mixes of aggregate blending, with a $19 \mathrm{~mm}$ nominal maximum aggregate size (MAZ) and optimum bitumen content were prepared and compacted using an automatic compactor to obtain cylindrical samples. The final compacted test cylinders of $150 \mathrm{~mm}$ diameter and $50 \mathrm{~mm}$ thickness were obtained. Each sample was cut into two halves to create semicircular test specimens. Six semicircular specimens were prepared for each mix, three used as smooth specimens and three used as cracked specimens. A notch of $15 \mathrm{~mm}$ depth was sawn into the flat side of specimens opposite to the curved side, to prepare the cracked specimens.

The testing machine, SCB test fixture, and SCB specimen are shown in Fig. 2. Test procedure followed AASHTO specifications $(2015,2016)$. The loading rate of $50 \mathrm{~mm} / \mathrm{min}$ was applied and remained constant during the test. The 
specimen placed centered on two rollers $127 \mathrm{~mm}$ apart with the notched side down. A vertical load was applied along the radius of the specimen. Load and central deflection (load line displacement, LLD) are traced during the test.
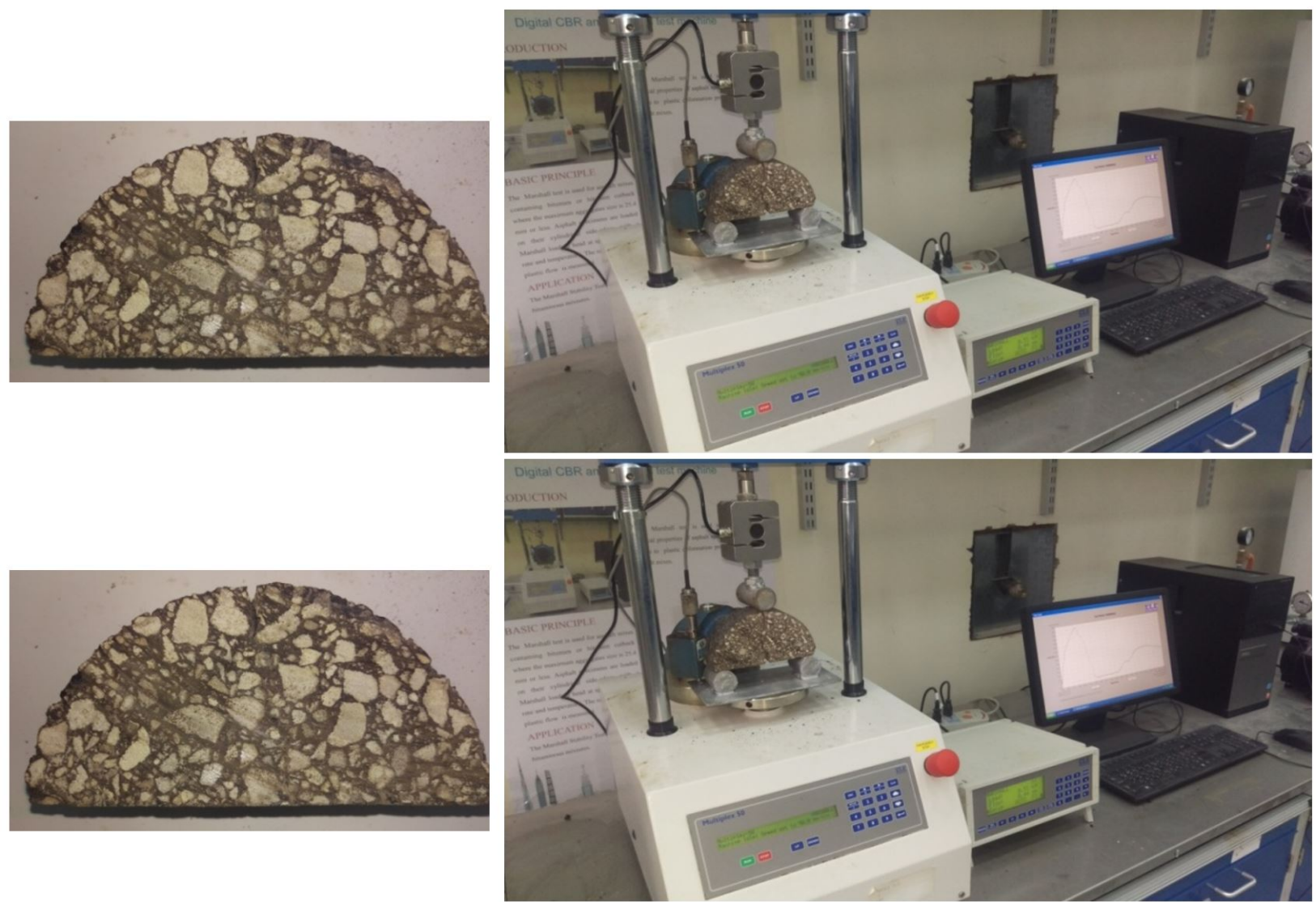

Figure 2: Test specimen and test setup.

\section{RESULTS AND DISCUSSION}

Since asphalt-aggregate interface is the weakest region in all tested materials, the cracks grow through this interface, i.e., the type of failure is intergranular fracture as shown in Fig. 3. The bond strength of the interface depends on the compatibility between the bitumen and aggregate as mentioned by Ji et al. (2017). As is already known, there are two different types of bond strength of the interface, i.e. the adhesion and cohesion bond strengths. Cohesion depends on the rheological properties of the asphalt binder, which was developed in the asphalt mastic and asphalt binder mixed with fine aggregate. The adhesive bond strength consists of chemical, surface energy, and mechanical adhesion. Ahmed et al. (2018) found that the Polyethylene (PE) wax-based Warm Mix Asphalt additive improved the bond strength of the interface. The same observation was found by Moraes et al. (2011). They concluded that additives improved both the adhesion and the cohesion bond strengths.
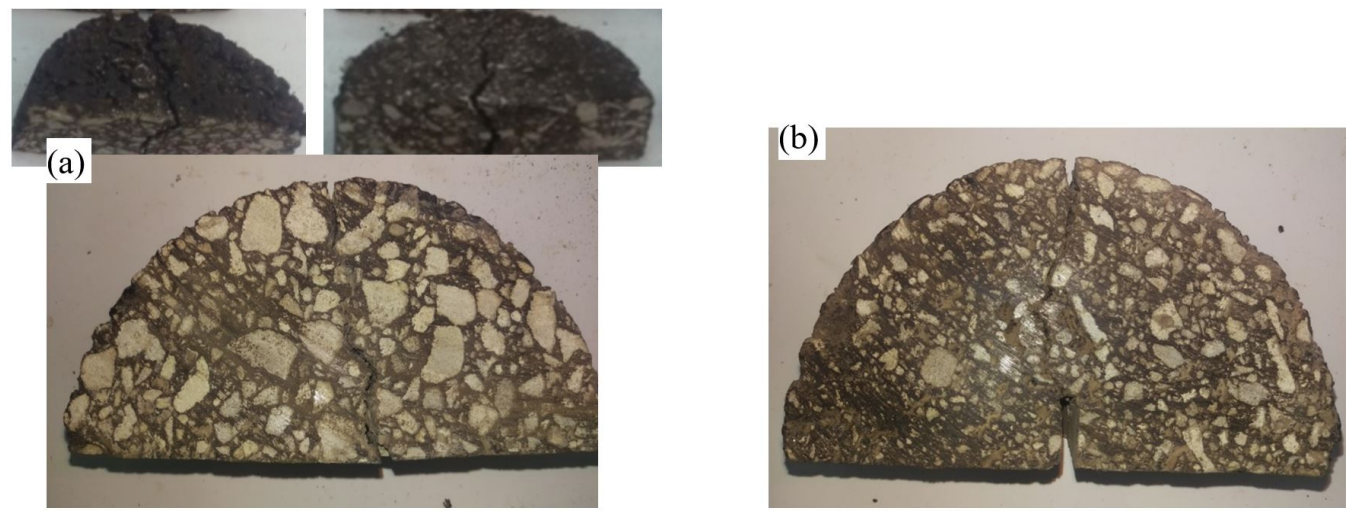

Figure 3: Specimen after testing for (a) smooth specimen and (b) cracked specimen 


\subsection{A comparison between the relationships of P-LLD curve}

In AASHTO TP 105-13 (2015), work of fracture, $W_{f}$ (Joules), calculated from load-load line displacement (P-LLD) curve, i.e. area under the whole curve, is based on the actual measurements by using quadrangle rule. However in AASHTO TP 124-16 (2016), the area under the whole P-LLD curve is calculated using a numerical integration technique. This technique has been applied by dividing the raw data of P-LLD into two parts, i.e. the ascending part and the descending part, and represented by appropriate equations. AASHTO TP 124-16 (2016) suggested that the $3^{\text {rd }}$-order polynomial equation is sufficient to fit the ascending part, while an exponential-based function is appropriate to fit the descending part as follows:

$y=\sum_{i=1}^{n} d_{i} \exp ^{\left[-\left(\frac{x-e_{i}}{f_{i}}\right)^{2}\right]}$

where: $d, e, f=$ polynomial coefficients, and $n$ is the number of exponential terms. In the descending part, there is an obvious point $(\mathrm{m})$ which is the inflection point. The slope of the tangential curve drawn at the inflection point represents post-peak slope, $m$, which is used in calculating Flexibility Index, (a dimensionless quantity), $F I=0.01\left(G_{f} /|m|\right)$. Where, $G_{f}=\left(W_{f} /\right.$ Area $\left._{\text {lig }}\right) \times 10^{6}\left(\left(\right.\right.$ Joules $\left./ \mathrm{m}^{2}\right)$, and $A r e a_{l i g}=$ ligament area, ligament length $\mathrm{x}$ specimen thickness $\left(\mathrm{mm}^{2}\right)$. It is worth noting that

P-LLD data for one specimen of each group are presented in Fig. 4.a for smooth specimens and in Fig. 4.b for cracked specimens. Comparatively, the shape of these data differs from the schematic curve presented in AASHTO TP 124-16, see Fig. 4 in AASHTO TP 124-16 (2016). Therefore, a comparison between the aforementioned techniques, in addition to a suggested present relation, has been made and presented in Fig. 5 for smooth and cracked specimens made of virgin materials. For simplicity and without any defect in accuracy, quad-linear curve has been suggested to fit both parts of the P-LLD curve. In the ascending part, the first line of the quad-linear curve represents the elastic behavior of the material and the second line represents the nonlinear behavior of the material. The end of the second line represents the point of ultimate load. The intersection between the third line and the fourth line of the quad-linear curve represents the inflection point $(\mathrm{m})$, and the slope of the third line represents post-peak slope. A comparison between the experimental (observed) results and predicted (fitted) values from the present quad-linear curve has been provided using the most general definition of the coefficient of determination, R-squared $\left(\mathrm{R}^{2}\right)$, as follows (Kutner et al., 2005):

$R^{2}=1-\frac{S S E}{S S T O}$

where: SSTO is the total sum of squares, SSTO $=\mathrm{SSE}+\mathrm{SSR}=\sum_{i=1}^{n}\left(y_{i}-\bar{y}\right)^{2}$, SSE is the error sum of squares, SSE $=\sum_{i=1}^{n}\left(y_{i}-\hat{y}_{i}\right)^{2}$, and SSR is the regression sum of squares, $\mathrm{SSR}=\sum_{i=1}^{n}\left(\hat{y}_{i}-\bar{y}\right)^{2}$. $y_{i}$ denotes the observed (measured) response for experimental term " $\mathrm{i}$ ", i ranged from 1 to $\mathrm{n}, \hat{y}_{i}$ is the predicted value for the experimental (measured) $y_{i}$, and $\bar{y}$ is the mean of the observed (measured) data.
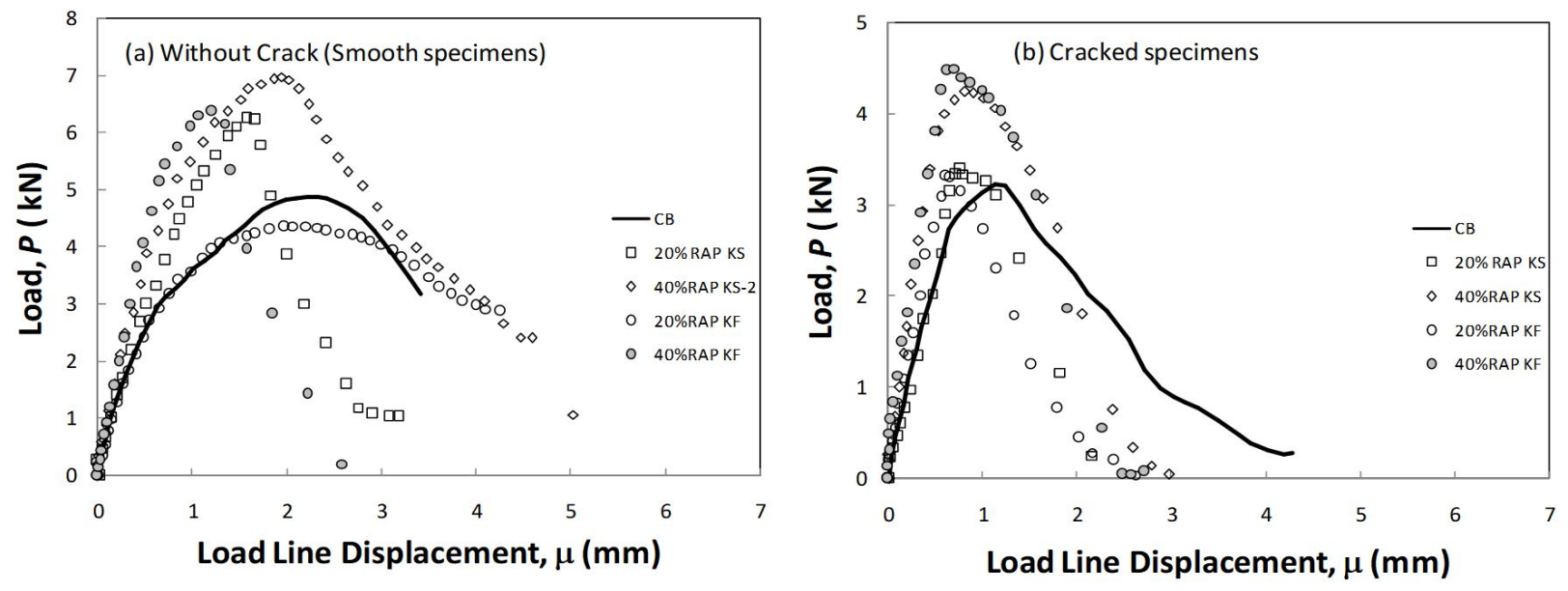

Figure 4: P-LLD curves for (a) smooth specimen and (b) cracked specimen 
Both the suggestion of AASHTO TP 124-16 (2016) and the present quad-linear curve fitted well the ascending part of the data as shown in Figs. 5.a to 5.d, i.e. $R^{2}>0.95$. However, both of them can not fit well the data in the descending part due to large scattering (differences) between the results of the replicas of these specimens. This may be attributed to the differences in the crack trajectory in each replica of these specimens, as shown in Fig. 6 . On the other hand, the present quad-linear relation is easier and more reasonable for presenting the experimental results especially for the descending part of P-LLD curve, than that suggested as exponential curve by AASHTO TP 124-16, Eq. 5. Furthermore, $R^{2}$ for descending part in quad-linear of smooth and cracked specimens are about 1.3 times and 4.5 times those of exponential curve suggested by AASHTO TP 124-16, respectively. The calculated values of the ultimate load and the work of fracture according to the actual data, the suggestion of AASHTO TP 124-16, and the present quad-linear curve shows that quad-linear curve is a simple and appropriate method to describe such data, as shown in Fig. 5.

\subsection{Smooth specimens}

Figure 7 shows P-LLD curves of smooth specimens for all RAP groups. Once again, $R^{2}$ for the whole data (ascending and descending parts) fitted by quad-linear relation is greater than 0.9 for all smooth specimens made of different RAP. There is a dilemma, which is that accurate calculation of ultimate tensile strength (UTS) of the material can't be made through SCB specimen, due to the discrepancy in the suggested equations in the literature.
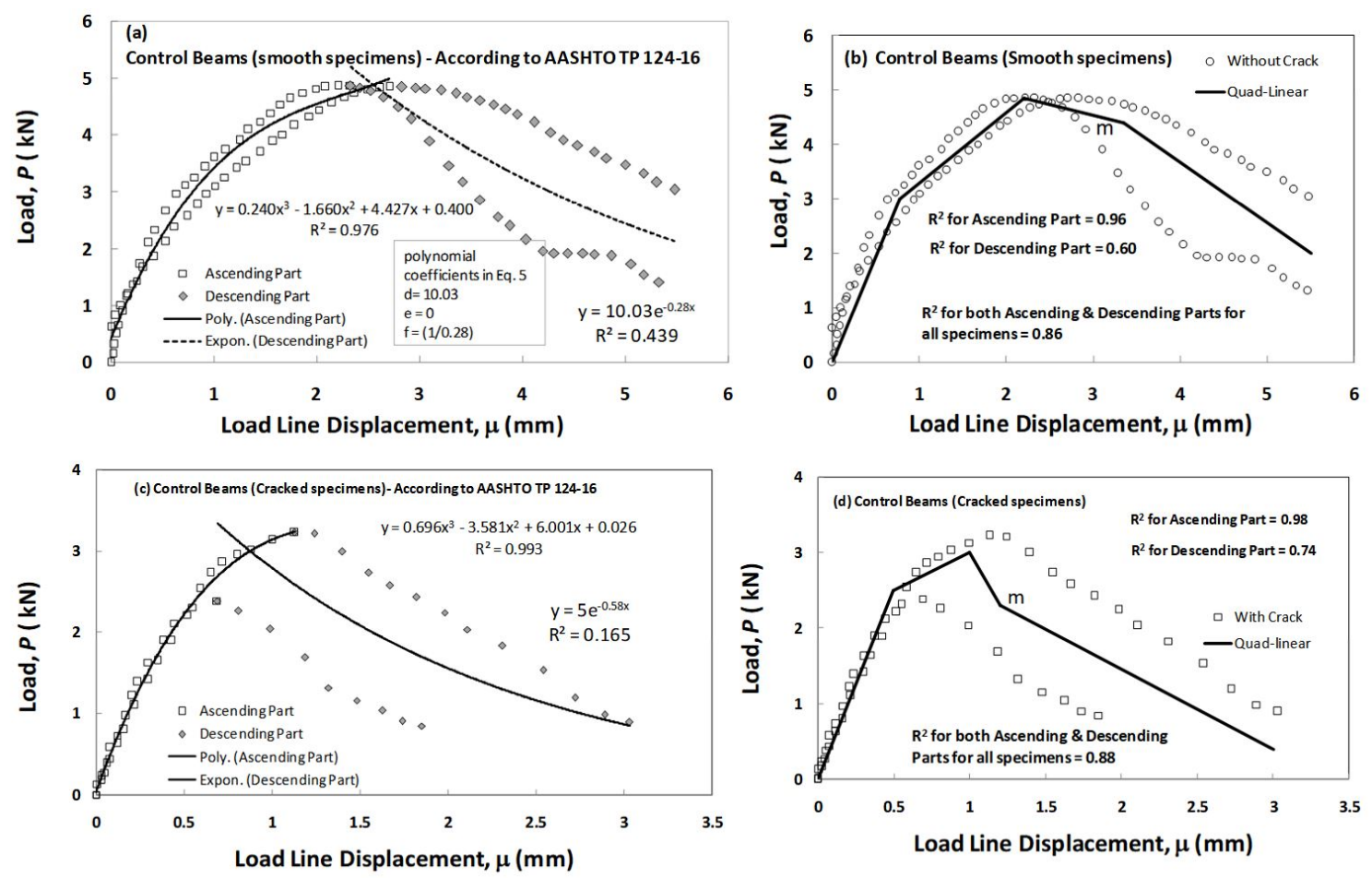

Figure 5: P-LLD curves for ( $a \& b$ ) smooth specimen and (c \& d) cracked specimen

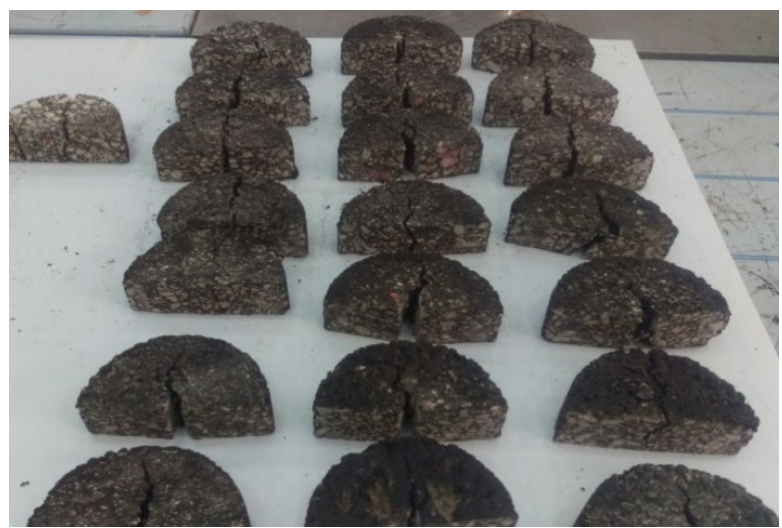

Figure 6: Crack trajectories in different replicas of the present specimens 
For example Van de Ven et al. (1997) suggested the following equation to determine the maximum tensile stress in smooth SCB specimen based on plain strain hypothesis and $\mathrm{S} / \mathrm{R}=0.8, D=2 R=150 \mathrm{~mm}$ and $t=50 \mathrm{~mm}$ :

$\sigma_{t}(S C B)=\frac{4.263 P_{\max }}{2 R t}$

Equation 7 was accepted by EN 12697-44 (2010). Yu (2009) suggested another relation close to the above, as shown in

$\sigma_{t}(S C B)=\frac{4.976 P_{\max }}{2 R t}$

It is clear that, the UTS calculated based on Eq. 7 (recommended by EN 12697-44) is lower than 0.9 that based on Eq. 8 (Yu, 2009). For the sake of reliability, Eq. 7 has been examined using $d_{\text {max }}$ concept (Sallam et al., (2014). The results of ultimate load, secant stiffness, $S$, post-peak slope, $m$, work of fracture, $W_{f}$, fracture energy, $G_{f}$, and flexibility index, $\mathrm{Fl}$, of smooth specimens of all groups are calculated in Table 6 base on the present quad-linear relation. It can be seen that the replacement of RAP increased the ultimate load for all percentage and type of RAP except $20 \%$ RAP-KF.
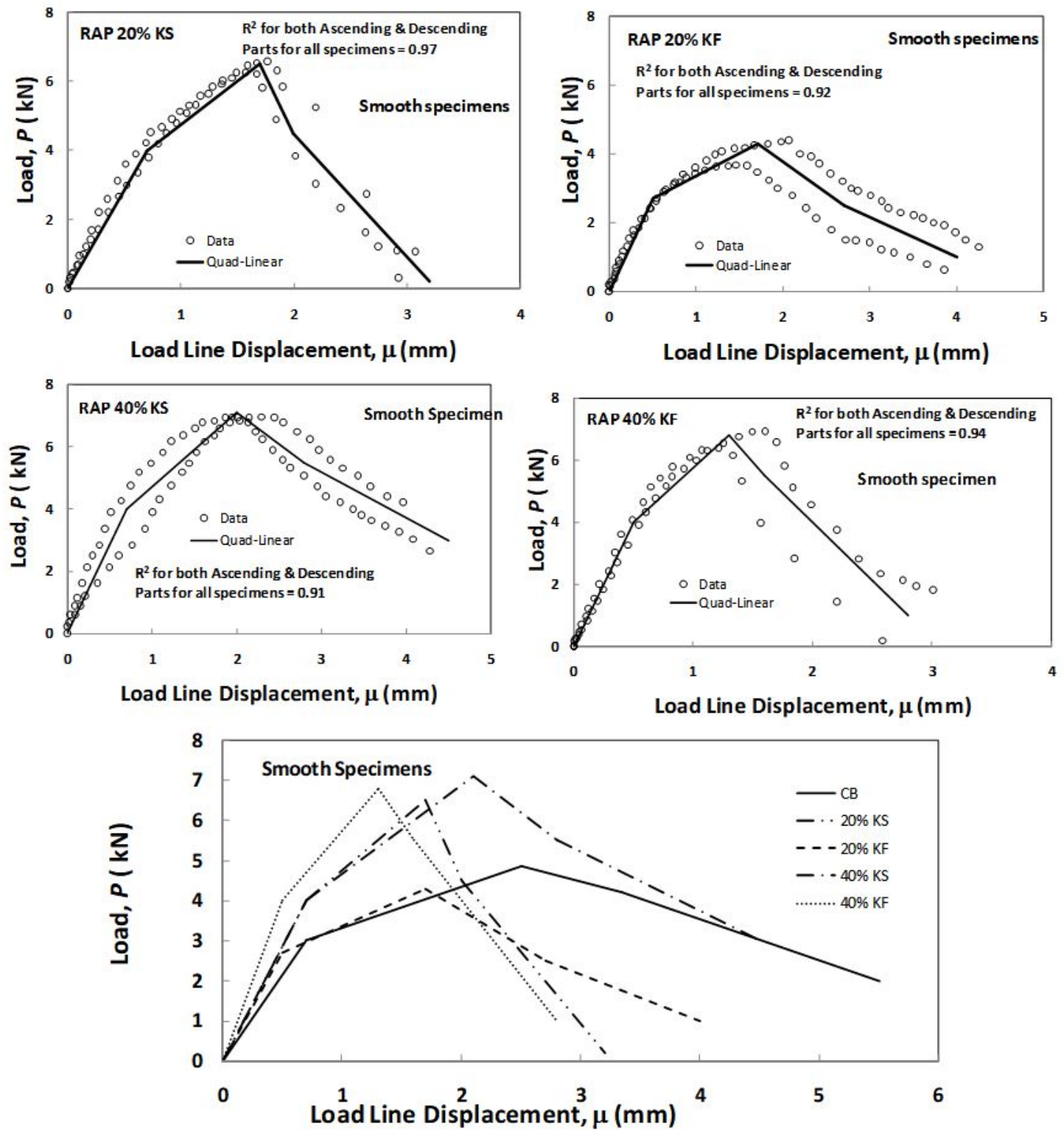

Figure 7: P-LLD curves for smooth specimens 
Table 6: Ultimate load, secant stiffness, post-peak slope, work of fracture, fracture energy, and flexibility index of all groups

\begin{tabular}{|c|c|c|c|c|c|c|c|}
\hline \multicolumn{3}{|c|}{ Material } & CB & $20 \% \mathrm{KS}$ & $20 \% \mathrm{KF}$ & $40 \%$ KS & $40 \% \mathrm{KF}$ \\
\hline \multirow{9}{*}{ 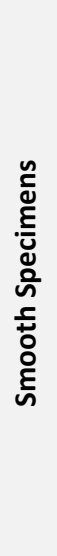 } & \multicolumn{2}{|c|}{ Pmax, kN } & 4.85 & 6.5 & 4.3 & 7.1 & 6.8 \\
\hline & \multicolumn{2}{|c|}{ Displacement, $\delta$, at Pmax, mm } & 2.2 & 1.7 & 1.7 & 2 & 1.3 \\
\hline & \multicolumn{2}{|c|}{ Secant stiffness, $S, \mathrm{kN} / \mathrm{mm}$} & 2.21 & 3.824 & 2.529 & 3.55 & 5.231 \\
\hline & \multicolumn{2}{|c|}{ Post-peak slope, $m, \mathrm{kN} / \mathrm{mm}$} & -1.06 & -6.67 & -1.8 & -2 & -4.33 \\
\hline & \multirow{3}{*}{ 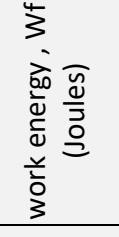 } & Ascending & 6.77 & 6.65 & 4.88 & 8.62 & 5.32 \\
\hline & & Descending & 12.2 & 4.47 & 5.67 & 12.26 & 5.75 \\
\hline & & Total & 18.63 & 11.12 & 10.55 & 20.81 & 11.07 \\
\hline & \multicolumn{2}{|c|}{ Fracture energy, $G f$ (Joules $/ \mathrm{m}^{2}$ ); } & 4968 & 2965 & 2813 & 5549 & 2952 \\
\hline & \multicolumn{2}{|c|}{ Flexibility Index (FI) } & 47 & 4 & 16 & 28 & 7 \\
\hline \multirow{9}{*}{ 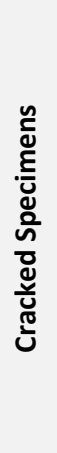 } & \multicolumn{2}{|c|}{ Pmax, kN } & 3 & 3.4 & 3.6 & 4.7 & 4.8 \\
\hline & \multicolumn{2}{|c|}{ Displacement, $\delta$, at Pmax, mm } & 1 & 0.8 & 0.8 & 1 & 0.8 \\
\hline & \multicolumn{2}{|c|}{ Secant stiffness, $S, \mathrm{kN} / \mathrm{mm}$} & 3 & 4.25 & 4.5 & 4.7 & 6 \\
\hline & \multicolumn{2}{|c|}{ Post-peak slope, $m, \mathrm{kN} / \mathrm{mm}$} & -3.5 & -1.29 & -2.67 & -1.2 & -1.6 \\
\hline & \multirow{3}{*}{ 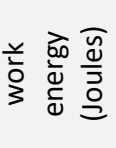 } & Ascending & 2 & 1.57 & 1.71 & 3.15 & 2.16 \\
\hline & & Descending & 2.96 & 3.56 & 3.15 & 6.8 & 4.9 \\
\hline & & Total & 4.96 & 5.13 & 5.04 & 9.95 & 7.06 \\
\hline & \multicolumn{2}{|c|}{ Fracture energy, $G f$ (Joules $/ \mathrm{m}^{2}$ ); } & 1653 & 1710 & 1680 & 3317 & 2353 \\
\hline & \multicolumn{2}{|c|}{ Flexibility Index (FI) } & 5 & 13 & 6 & 28 & 15 \\
\hline
\end{tabular}

However, the opposite was observed for work of fracture except in the case $40 \%$ RAP-KS. It is worth noting that replacement of $40 \%$ RAP-KS increased the ultimate load and work of fracture of flexible pavement by about $45 \%$ and $10 \%$, respectively. The concepts of fracture energy and flexibility index suggested by AASHTO TP 124-16 (2016) were implemented for smooth specimens by equating the length of ligament with the radius of the specimen (whole the specimen height). Fl ranged between 4 and 47 for smooth specimens. On the other hand, Ozer et al. (2016) concluded that "the range of $\mathrm{Fl}$ values for the laboratory produced mixes was in the range from 2 to 16 with an increasing brittleness with lower $\mathrm{Fl}$ values". As mentioned by Ozer et al. (2016), Fl may be considered as a parameter of process zone size or other combinations with a good correlation to crack growth speed.

\subsection{Cracked specimens}

Figure 8 shows P-LLD curves of cracked specimens for all RAP groups. As found in smooth specimens, $\mathrm{R}^{2}$ is equal to or greater than, $\geq, 0.9$ for the whole data of all cracked specimens (ascending and descending parts) fitted by quad-linear relation. The results of ultimate load, secant stiffness, $S$, post-peak slope, $m$, work of fracture, $W_{f}$, fracture energy, $G_{f}$, and flexibility index, $\mathrm{Fl}$, of cracked specimens of all groups are calculated in Table 6 base on the present quad-linear relation. For all percentages and types of RAP, the flexible pavement containing RAP has higher ultimate load and work of fracture than those of flexible pavement without RAP. The ultimate load and work of fracture are increased by increasing the RAP percentage. Since there are only small differences between the properties constituting the two sources of RAP, the RAP source has a marginal effect. Fl ranged between 5 and 28 for cracked specimens. AASHTO TP 124-16 (2016) suggested that $F I$ as a provider to recognize the brittleness of mixes. Service life and environmental conditions are the main parameters controlling the range for an acceptable. The comparison between the values of $\mathrm{FI}$ measured from the smooth specimens and those from cracked specimens revealed that there is no clear trend for $\mathrm{Fl}$, some values increased, others decreased, and the rest kept constant, see Table 6. Furthermore, Ozer et al. (2016) suggested three different relations to calculate $\mathrm{Fl}$, one of them as suggested by AASHTO TP 124-16 (2016). Therefore, the concept of $F /$ should be reviewed and needs extra work to be verified.

The fracture toughness according to AASHTO TP 105-13 has been calculated as follows:

$K_{I C}=\sigma_{0} Y_{I(0,8)} \sqrt{\pi a}$ 
$\sigma_{o}=\frac{P_{\max }}{2 R t}$

$Y_{I(0.8)}=4.782+1.219\left[\frac{a}{R}\right]+0.063 \exp \left[7.045\left[\frac{a}{R}\right]\right]$

It is clear that, when "a" approaches zero $Y_{I(0.8)}=4.845$, i.e., it is close to the constant in equations 7 and 8 . Figure 9 shows that the fracture toughness increased by increasing the RAP\% for both types of RAP. To examine the equation of UTS calculated by Eq. 7 with $d_{\max }$ concept as mentioned above, the examination of the set of equations calculated the fracture toughness according to EN 12697-44 (2010) has been made first. This examination shows two severe drawbacks as follows: First, the fracture toughness equation is not compatible from the units point of view:

$K_{I C}=\sigma_{\max } \times f\left(\frac{a}{w}\right)\left(M_{P a m^{0.5}}\right)$

$f\left(\frac{a}{w}\right)=-4.9965+155.58\left[\frac{a}{w}\right]-799.94\left[\frac{a}{w}\right]^{2}+2141.9\left[\frac{a}{w}\right]^{3}-2709.1\left[\frac{a}{w}\right]^{4}+1398.6\left[\frac{a}{w}\right]^{5}$ Dimensionless

and $\sigma_{\max }$ as suggested by Van de Ven et al. (1997), Eq. 1 in MPa. Then, from the units point of view

$$
K_{I C}\left(M_{P a m}^{0.5}\right) \neq \sigma_{\max }(M P a) \times f\left(\frac{a}{w}\right) \text { dimensionless }
$$

So, the term $\sqrt{\pi a}$ may be missed, see Eq. 5. Somé et al. (2018) claimed that the term $f\left(\frac{a}{w}\right)$ is defined as $f^{*}\left(\frac{a}{w}\right)$ and $f^{*}\left(\frac{a}{w}\right) \propto \sqrt{\pi a} \times f\left(\frac{a}{w}\right)$ but is still the same as defined in Eq. 13. Based on this argument, the second drawback arises when "a" approaches zero $f^{*}\left(\frac{a}{w}\right)=-5$, i.e., $K_{I C}$ becomes negative for short cracks! To overcome this dilemma, UTS of smooth specimen is calculated according to Eq. 7, while, $K_{I C}$ is calculated according to Eq. 9, then:

$d_{\max }=\frac{1}{\pi}\left(\frac{K_{I C}}{\mathrm{Y}_{\mathrm{I}(0,8)} \sigma_{t}(\mathrm{SCB})}\right)^{2}$

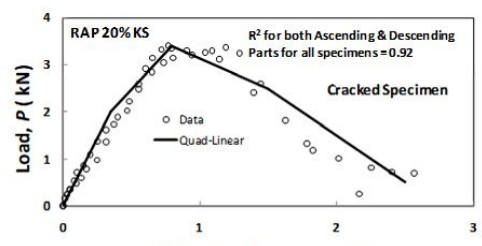

Load Line Displacement, $\mu$ ( $\mathrm{mm})$
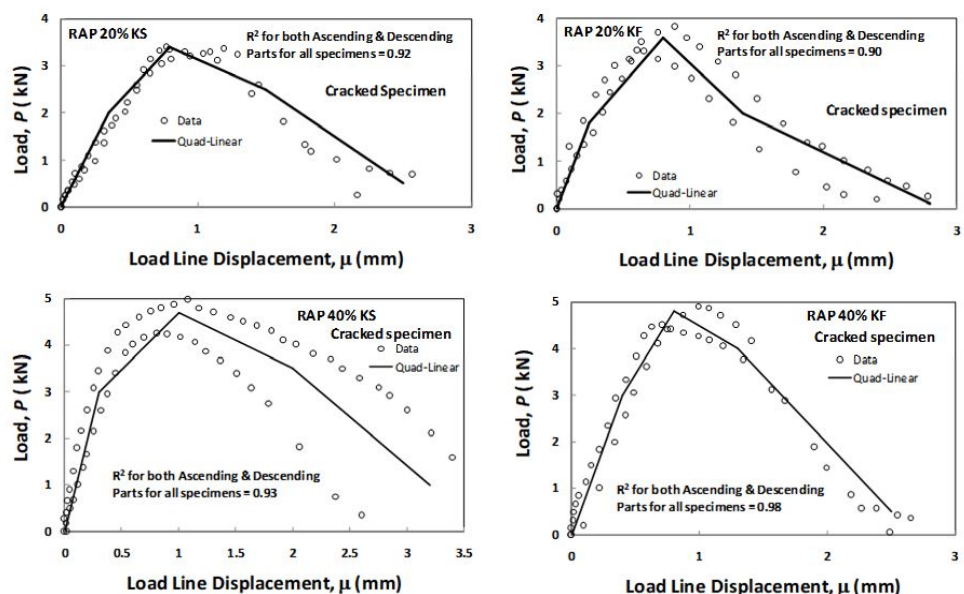

Load Line Displacement, $\mu(\mathrm{mm})$
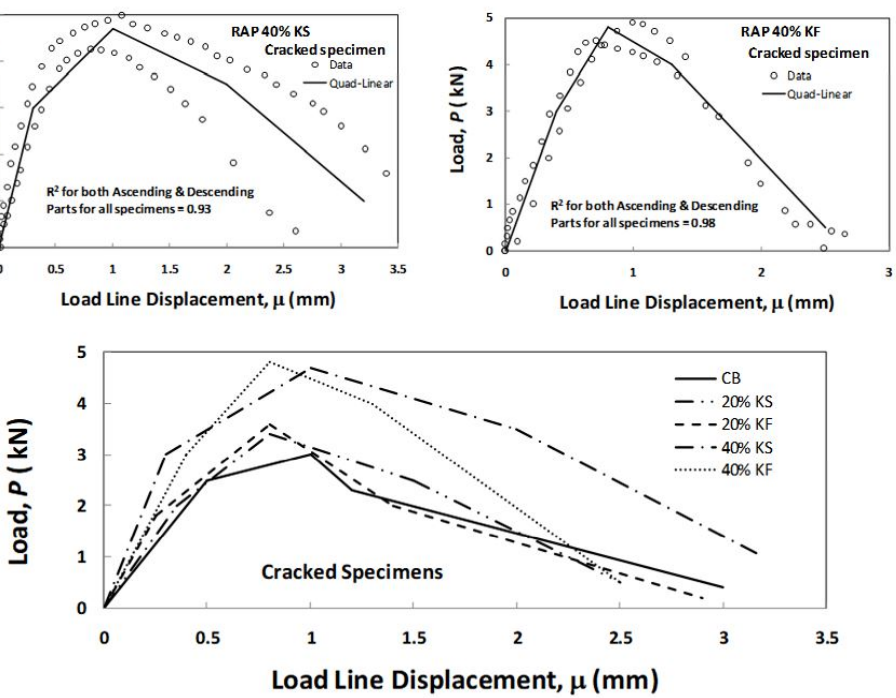

Figure 8: P-LLD curves for cracked specimens 
Figure 10 shows $d_{\max } / \mathrm{MAZ}$ based in Eq. 7 for different material. It is clear that, if all values of $d_{\max } / \mathrm{MAZ}$ are lower than unity, this means the maximum size of non-damaged defect is lower than the nominal maximum size of used aggregate and this is acceptable. It can be concluded that the equation of UTS of smooth specimens suggested by Van de Ven et al. (1997) and adopted by EN 12697-44 (2010) is more reliable than other equations found in the literature. However, the set of equations in EN 12697-44 (2010) should be reviewed and modified.

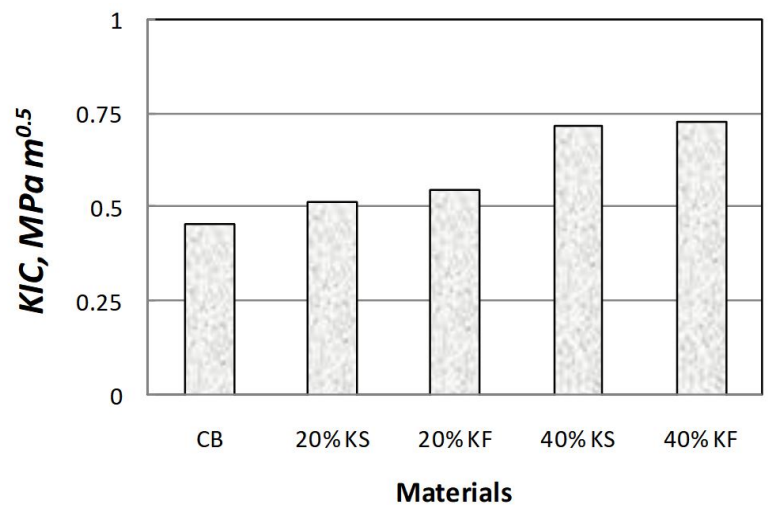

Figure 9: $\mathrm{K}_{\mathrm{IC}}$ for all groups.

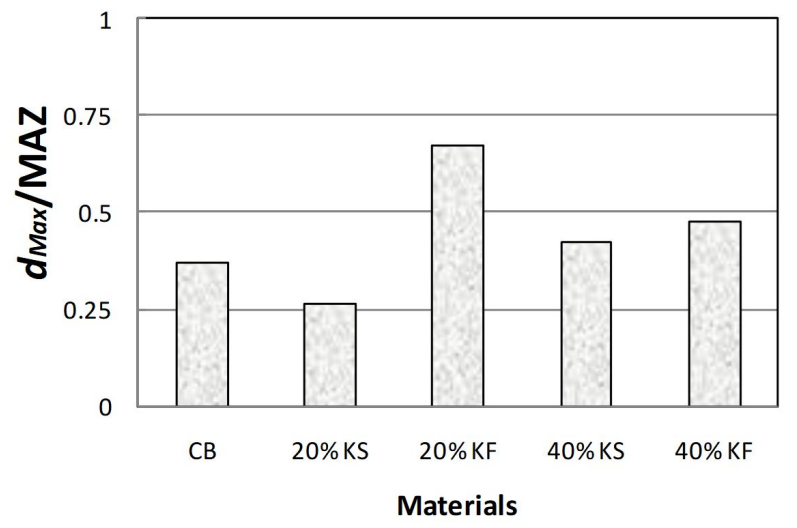

Figure 10: $d_{\max } /$ MAZ for all groups.

Furthermore, a comparison between the fracture energy calculated based on the whole area of P-LLD curve (AASHTO TP 124-16, 2016) and the area of the descending part only is shown in Fig. 11. Fracture energy for control beam and $20 \%$ RAP is almost the same, while, the $40 \%$ RAP showed superior fracture energy. As expected, the fracture energy calculated based on the area of the descending part is lower than that based on the area of the whole curve, and subsequently the value of modulus of elasticity predicted from the relation of $\left(K_{/ C}\right)^{2} / G_{f}$ has an opposite trend.

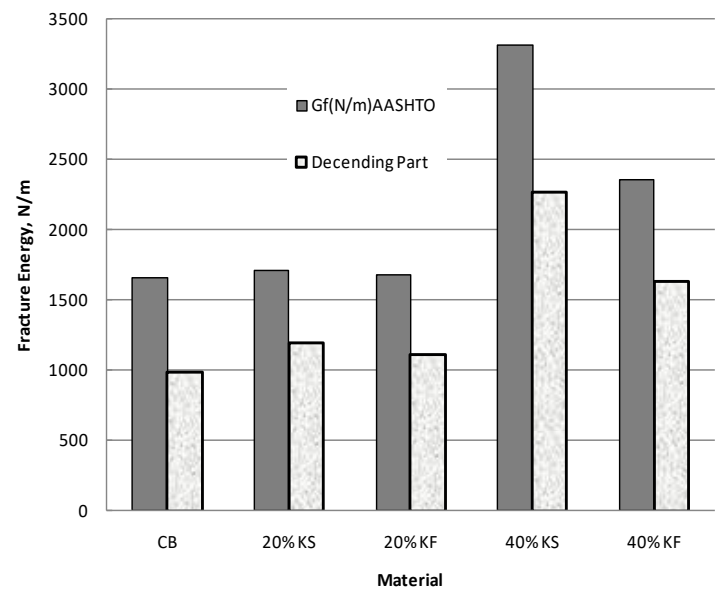

Figure 11: Fracture Energy for all groups. 


\section{CONCLUSION}

The experimental results of flexible pavement with and without RAP under static flexural loading for smooth and cracked specimens support the following conclusions:

1. For the two different types of RAP, the flexible pavement containing $40 \%$ RAP has higher flexural strength and mode-I fracture toughness than that of flexible pavement without RAP.

2. Since asphalt-aggregate interface is the weakest point in all tested materials, the type of failure is intergranularmode fracture.

3. Work of fracture calculated according to AASHTO TP 105-13 is more accurate than that calculated by AASHTO TP 124-16.

4. The suggested quad-linear curve is easier and more reasonable for presenting the experimental results of both parts (ascending and descending) of P-LLD curve than that suggested as two curves ( $3^{\text {rd }}$-order polynomial and exponential) by AASHTO TP 124-16.

5. The equation of UTS of smooth specimens in EN 12697-44 (2010) is more reliable than other equations found in the literature. However, the set of equations in EN 12697-44 (2010) should be reviewed and modified.

\section{References}

AASHTO TP105-13 (2015). Standard Method of Test for Determining the Fracture Energy of Asphalt Mixtures Using the Semicircular Bend Geometry (SCB). Washington, D.C. 20001, USA.

AASHTO TP 124-16 (2016). Standard Method of Test for Determining the Fracture Potential of Asphalt Mixtures Using Semicircular Bend Geometry (SCB) at Intermediate Temperature. Washington, D.C. 20001, USA.

Abdulshafi, O., Kedzierski, B., and Fitch, M. G. (2002). "Determination of Recycled Asphalt Pavement (RAP) Content in Asphalt Mixes Based on Expected Mixture Durability," Research Report FHWA/OH-2002/037, Ohio State University, Columbus, OH.

Abou El-Mal, H.S., Sherbini, A.S., and Sallam, H.E.M., 2015. Mode II Fracture Toughness of Hybrid FRCs. International Journal of Concrete Structures and Materials, 9, 475-486.

Abtahi, S.M., Sheikhzadeh, M., and Hejazi, S.M. (2010). Fiber-reinforced asphalt-concrete - A review.Construction and Building Materials24 (2010) 871-877.

Ahmed, T.A., Lee, H.D., Williams, R.C. (2018). Using a modified asphalt bond strength test to investigate the properties of asphalt binders with poly ethylene wax-based warm mix asphalt additive.International Journal of Pavement Research and Technology Vol. 11, 28-37.

Al Hazmi, H.S.J.; Al Hazmi, W.H.; Shubaili, M.A.; Sallam, H.E.M.: Fracture Energy of Hybrid Polypropylene-Steel Fiber High Strength Concrete, HPSM 2012, 18-20 June, New Forest, UK, High Performance Structure and Materials, vol. VI, pp. 309-318 (2012). doi:10.2495/HPSM120271.

Al-Qadi, I.L., Elseifi, M., Carpenter, S.H. (2014). Reclaimed Asphalt Pavement - A Literature Review. Report No. FHWA-ICT-07001. Illinois Center for Transportation Series No. 07-001, USA. UILU-ENG-2007-2014. ISSN: 0197-9191.

Cascione, A. A., Williams, R. C., Gillen, S.L., and Haugen, D.S. (2010). "Utilization of Post-Consumer Recycled Asphalt Shingles and Fractionated Recycled Asphalt Pavement in Hot Mix Asphalt," Mid-Continent Transportation Research Forum, University of Wisconsin-Madison, Madison, WI.

EN 12697-44, 2010. Bituminous Mixtures-Test Methods for Hot Mix Asphalt Part 44: crack Propagation by Semi-Circular Bending Test, European Committee for Standardization, Brussels, Belgium.

Ghabchi, R., Barman, M., Singh, D., Zaman, M., \&Mubaraki, M. A. (2016). Comparison of laboratory performance of asphalt mixes containing different proportions of RAS and RAP. Construction and Building Materials, 124, 343-351.

Hossiney, N., Tia, M., BerginM., (2010). Concrete Containing RAP for Use in Concrete Pavement.International Journal of Pavement Research and Technology.3(5):251-258

Ji, J., Yao, H., Liu, L., Sou, Z., Zhai, P., Yang, X., You, Z. (2017) Adhesion Evaluation of Asphalt-Aggregate Interface Using Surface Free Energy Method.Appl. Sci., 7, 156; doi:10.3390/app7020156. 
Johnson, E., Johnson, G., Dai, S., and Linell, D. (2010). "Incorporation of Recycled Asphalt Shingles in Hot-Mixed Asphalt Pavement Mixtures," Research Report MN/RC 2010-08, Minnesota Department of Transportation, St. Paul, MN.

Kim, S., Sholar, G. A, Byron, T. and Kim, J. (2009). "Performance of Polymer Modified Asphalt Mixture with Reclaimed Asphalt Pavement," Transportation Research Board 2009 Annual Meeting, CD-ROM Publication, Transportation Research Board, National Research Council, Washington D.C.

Kutner, M.H., Nachtsheim, C.J., Neter, J., Li, w. (2005). Applied linear statistical models, 5th ed. McGraw-Hill/Irwin, New York.

Li, X., Marasteanu, M., Williams, R. C., and Clyne, T. R. (2008). "Effect of RAP Proportion and Type and Binder Grade on the Properties of Asphalt Mixtures," Transportation Research Record, No. 2051, Journal of the Transportation Research Board, Washington, D.C., pp. 90-97.

McDaniel, R. S., and Shah, A. (2003). "Use of Reclaimed Asphalt Pavement (RAP) Under SuperPave Specifications," Journal of the Association of Asphalt Paving Technologists, Vol. 72, pp. 226-252.

Mogawer, W. S., Austerman, A. J., Bonaquist, R., and Roussel, M., (2011). "Performance Characteristics of Thin-Lift Overlay Mixtures High Reclaimed Asphalt Pavement Content, Recycled Asphalt Shingles, and Warm-Mix Asphalt Technology," Transportation Research Record, No. 2208, Journal of the Transportation Research Board, Washington, D.C., pp. 17-25.

Moraes, R., Velasquez, R., Bahia, H.U. (2011). Measuring the effect of moisture on asphalt-aggregate bond with the bitumen bond strength test. Transportation Research Record Journal of the Transportation Research Board, No. $2209, \cdot$ pp. 70-81.

Mousa, S., Abd-Elhady, A.A., Kim, G-Y., and Sallam, H.E.M. (2018). Fracture behavior of roll bonded Al-brass-Al multilayer composites - Concept of the maximum undamaged defect size $\left(d_{\max }\right)$.Structural Integrity Procedia, 13, 686-693.

Mubaraki, M., Abd-Elhady, A.A., and Sallam, H.E.M., (2013), "Mixed Mode Fracture Toughness of Recycled Tire Rubber-Filled Concrete for Airfield Rigid Pavements," International Journal of Pavement Research and Technology (6)1, pp. 8-14.

Mubaraki, M. A., Abd-Elhady, A. A., Osman, S. A., \&Sallam, H. E. M. (2017). Mixed mode fracture behavior of concrete pavement containing RAP-3D finite element analysis. Procedia Structural Integrity, 5, 19-26.

MubarakiM., Sallam, H.E.M. (2018). Reliability study on fracture and fatigue behavior of pavement materials using SCB specimen, International Journal of Pavement Engineering, In Press.

Naqi, D., Abbas, N., Zahra, N., Hussain, A., Shabbir, S.Q. (2018). Effect of multi-walled carbon nanotubes (MWCNTs) on the strength development of cementitious materials. Journal of Materials Research and Technology (jmr\&t), In Press.

Ozer, H., Al-Qadi, I.L., Lambros, J., El-Khatib, A., Singhvi, P., Doll, B. (2016). Development of the fracture-based flexibility index for asphalt concrete cracking potential using modified semi-circle bending test parameters., Construction and Building Materials, 115, 390-401.

Sallam, H.E.M.: Fracture energy of fiber reinforced concrete. Al-Azhar Univ.Eng. J.6, 555-564 (2003).

Sallam, H.E.M., Abd-Elhady, A.A., (2012) " Mixed mode crack initiation and growth in notched semi-circular specimens-Three dimensional finite element analysis", Asian Journal of Material Science, 4 (2), pp. 34-44.

Sallam, H.E.M., Abd-Elhady, A.A., (2013), "Crack Length-Effective Stress Intensity Factor Relation in Notched Semi-Circular Specimens for Different Mode of Mixity", Researches and Applications in Mechanical Engineering, 2 (4), pp. 120-124.

Sallam, H.E.M., Mubaraki, M. and Yusoff. N. (2014) "Application of the Maximum Undamaged Defect Size (dmax) Concept in Fiber Reinforced Concrete Pavements," Arabia Journal of Science and Engineering, Vol. 39, pp. 8499-8506.

Sallam, H.E.M., and Mubaraki, M., (2015), "Evaluation of the fracture energy methods used in fiber reinforced concrete pavements by the maximum undamaged defect size concept", 94th Annual Meeting of TRB, Washington, DC, USA.

Somé, S.C., Fredj, M.A., Nguyen, M., Feeser, A., Pavoine, A. (2018) Multi-parametric characterization of mode I fracture toughness of asphalt concrete: Influence of void and RA contents, binder and aggregate types. International Journal of Pavement Research and Technology, 11, 274-284.

Ulsen, C., Tseng, E., Angulo, S.C., Landmann, M., Contessotto, R., Balbo, J.T., Kahn, H. (2018). Concrete aggregates properties crushed by jaw and impact secondary crushing. Journal of Materials Research and Technology (jmr\&t), In Press.

Van de Ven, M., Smit, A., Krans, R. (1997). Possibilities of a semi-circular bending test, in: International Conference on Asphalt Pavements, Seattle, Washington, August 10-14, pp. 939-950. 
Yoo, D-Y., Kim, S., Kim, M-J., Kim, D., and Shin, H-O. (2018). Self-healing capability of asphalt concrete with carbon-based materials. Journal of Materials Research and Technology (jmr\&t), In Press.

Yu, L. (2009). Research on Dynamic Response and Fracture Performance of Asphalt Mixture Based on Semi-circular Bending Test[D]. Harbin: Harbin Institute of Technology, (in Chinese). 